\section{The case report (1)}

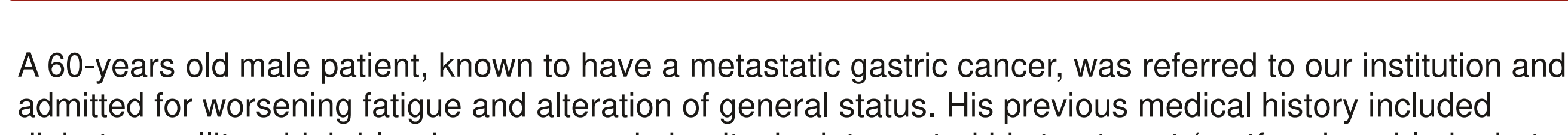

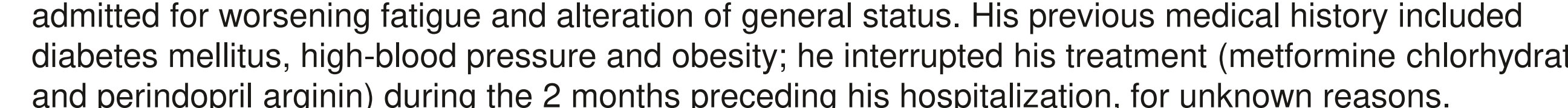

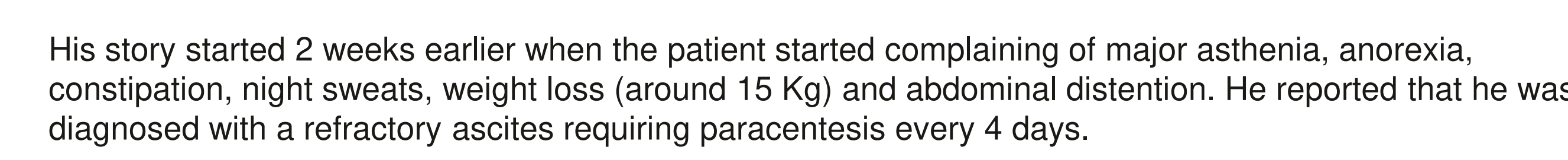

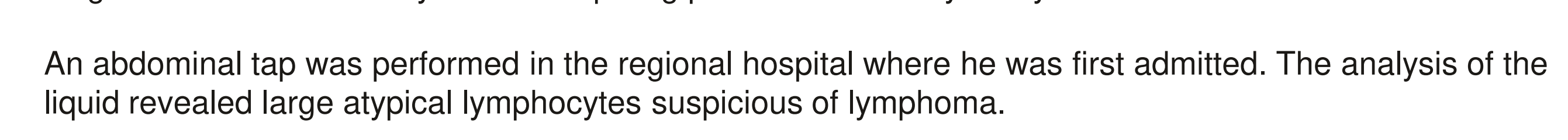

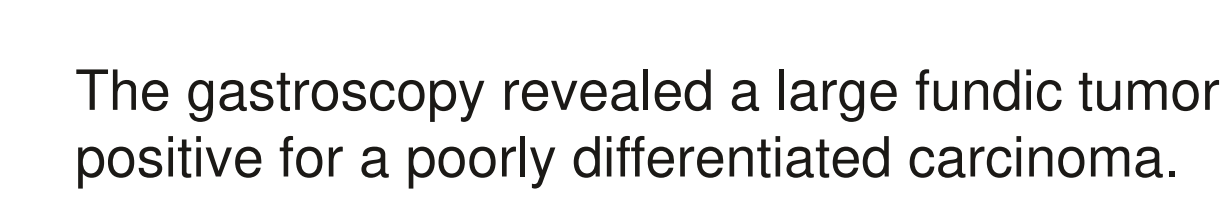

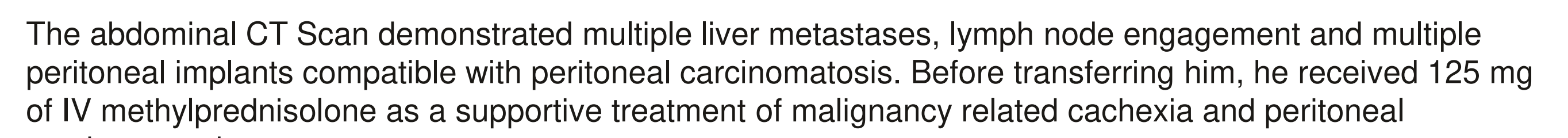

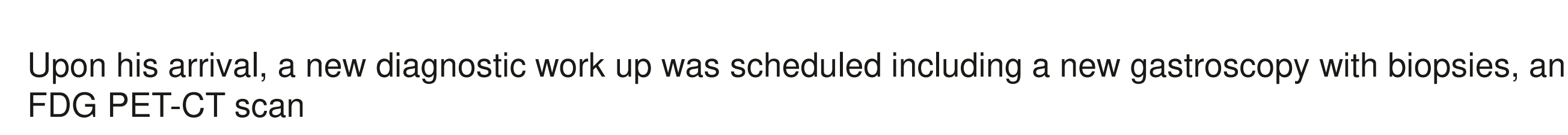

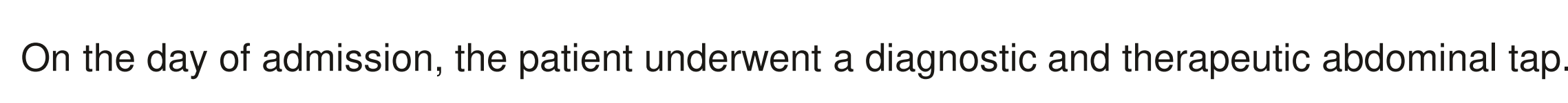

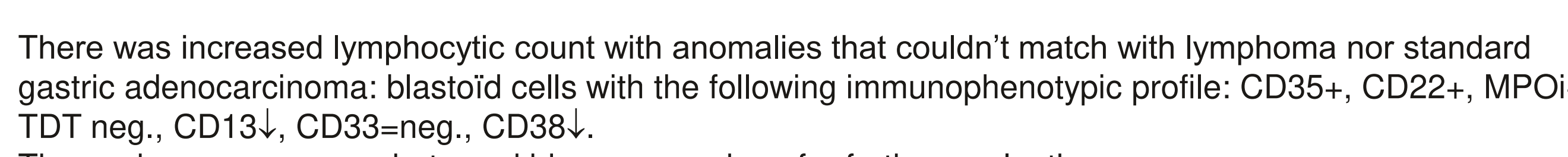

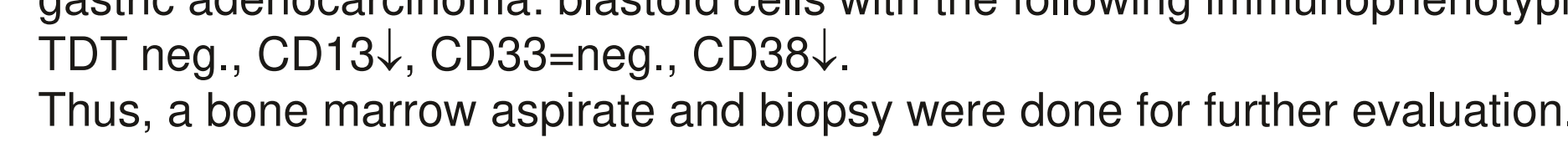
Lymphocytic counting gi ascities

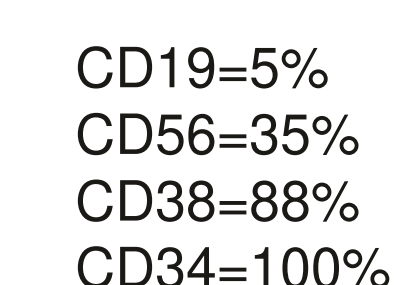

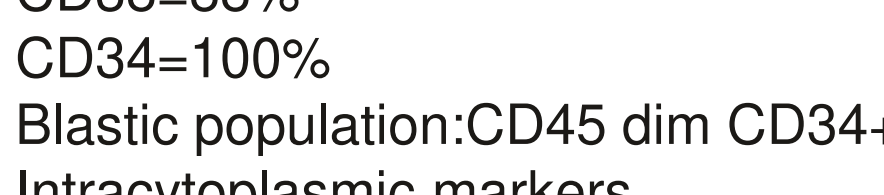

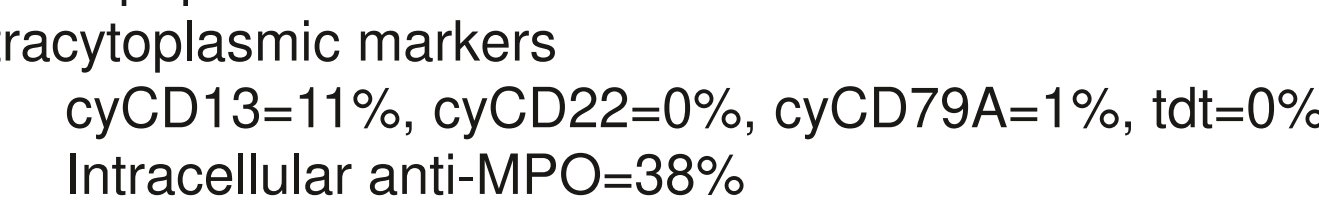

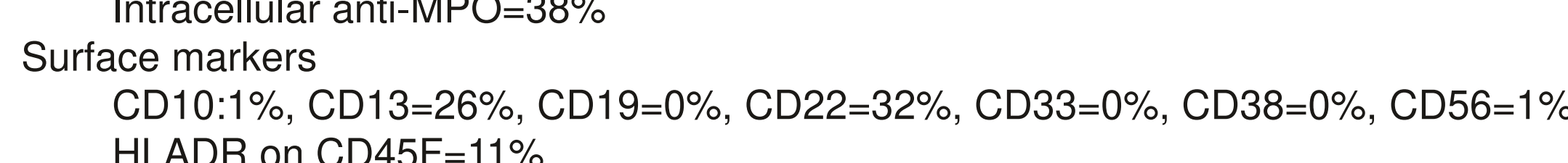

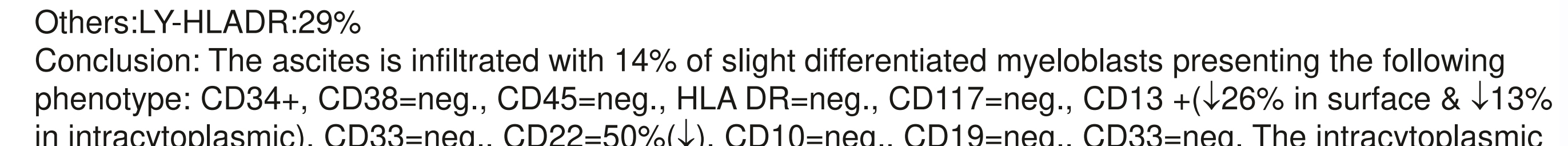

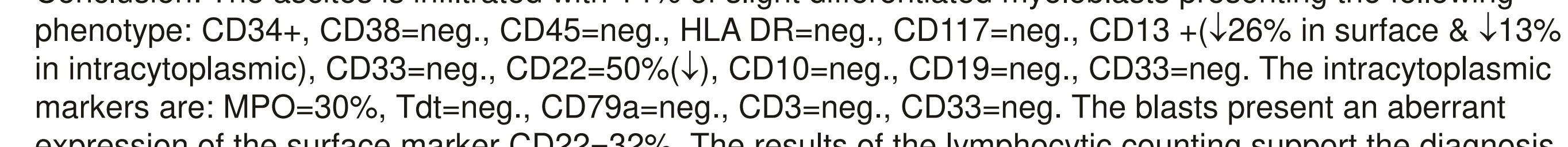

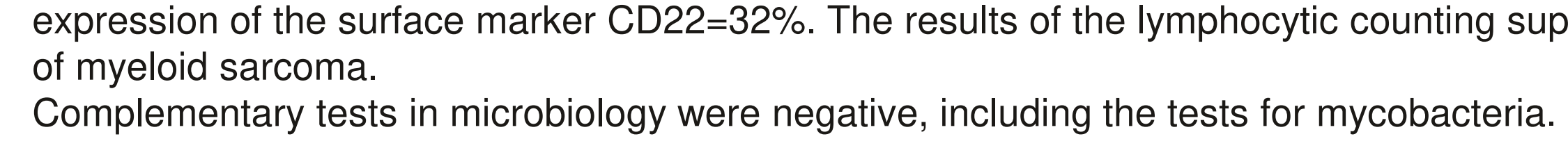
Bone marrow biopsy

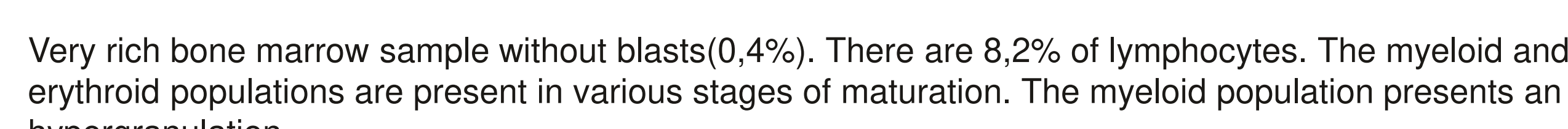

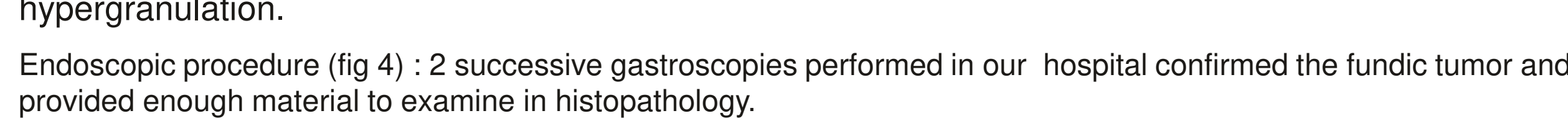

The case report (2)

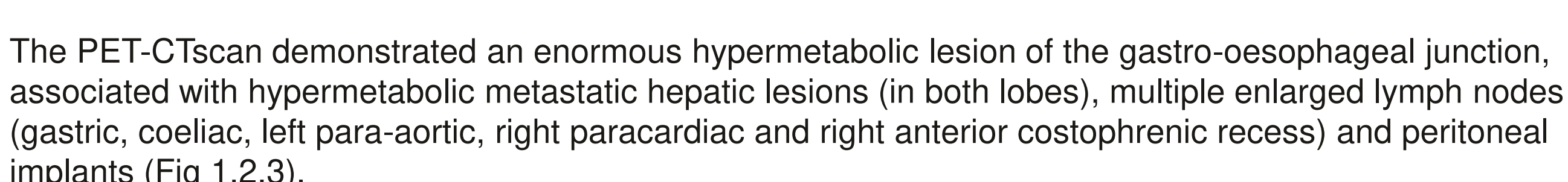
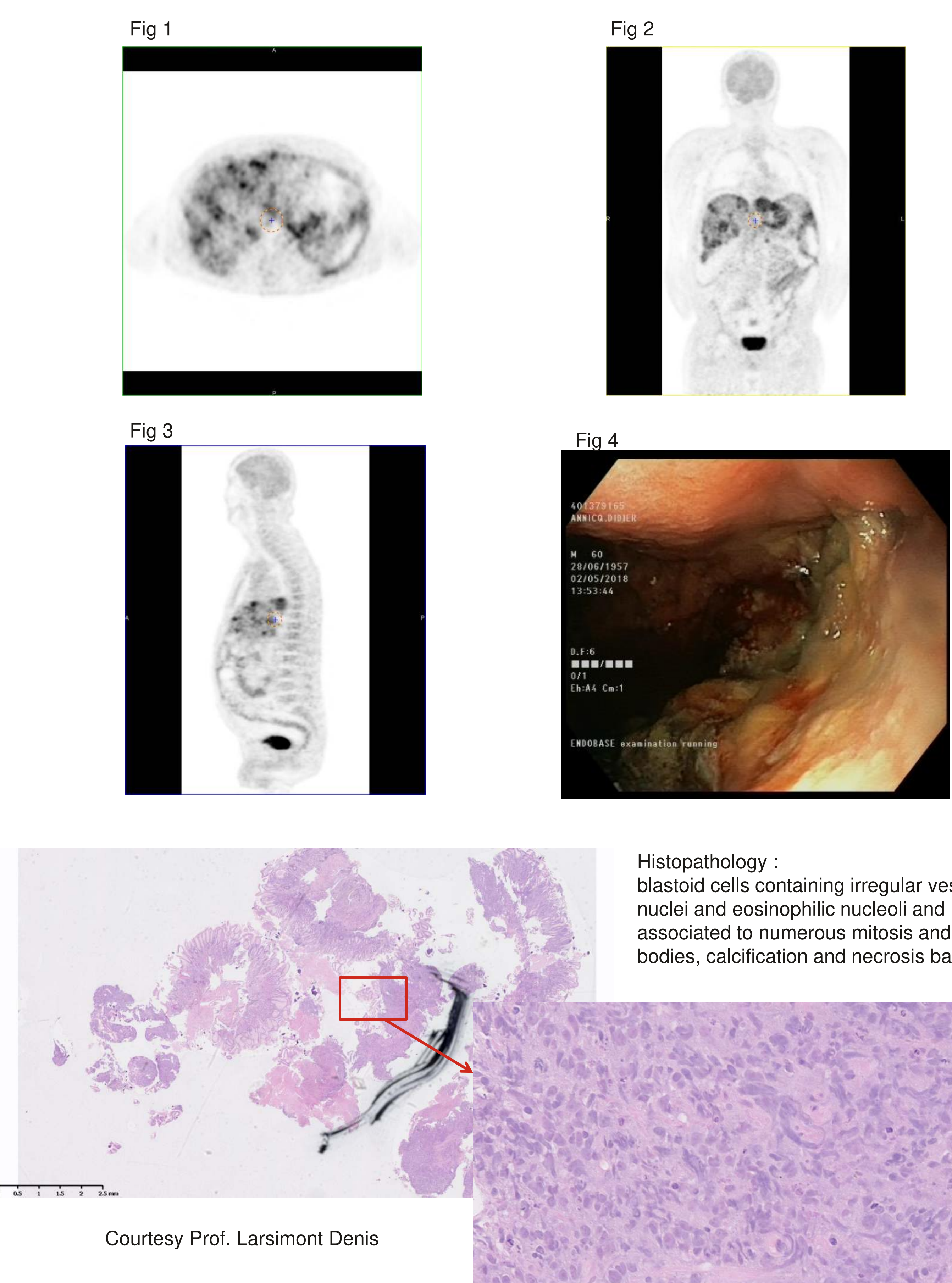

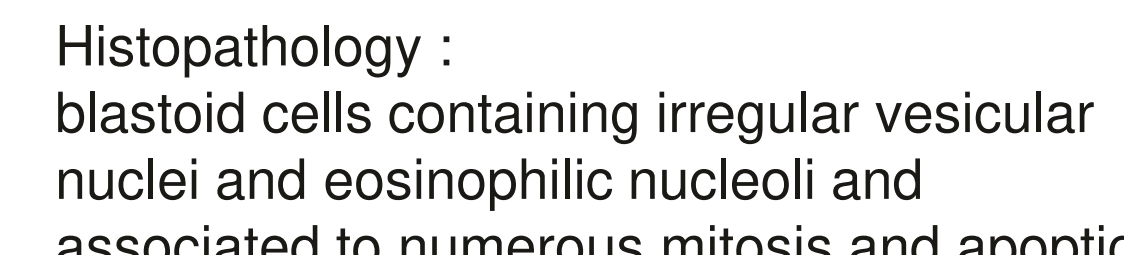

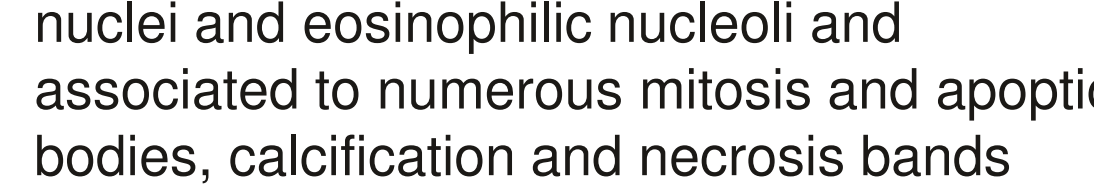

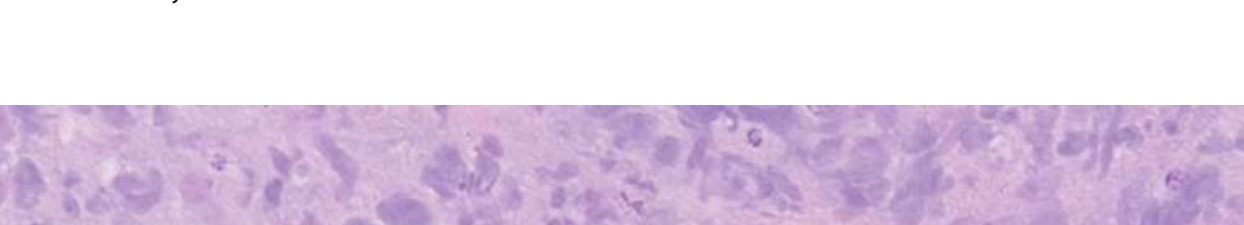

\section{The case report (3)}

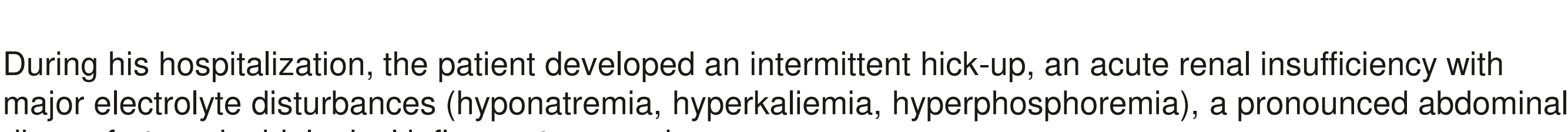

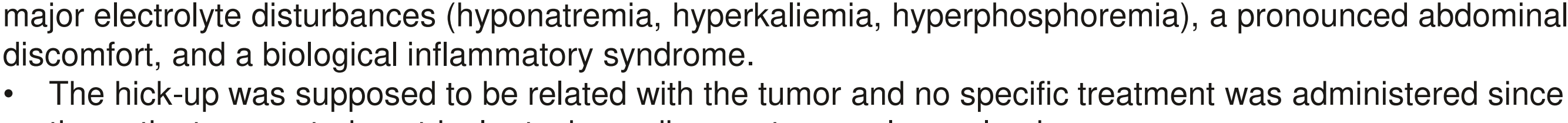

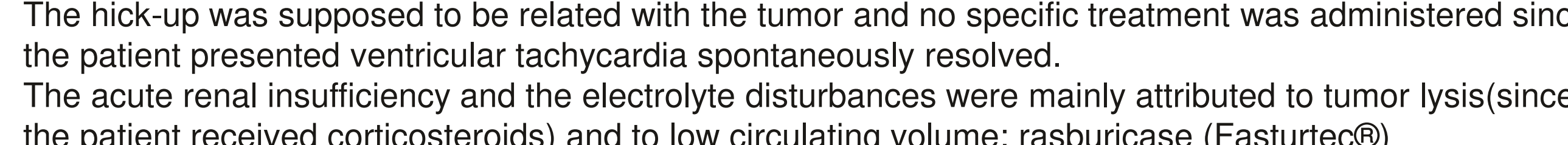

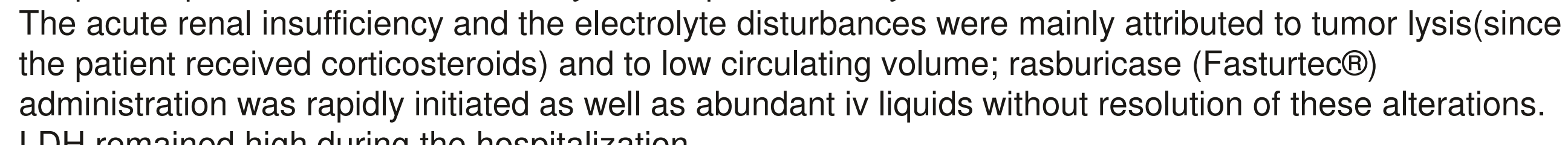

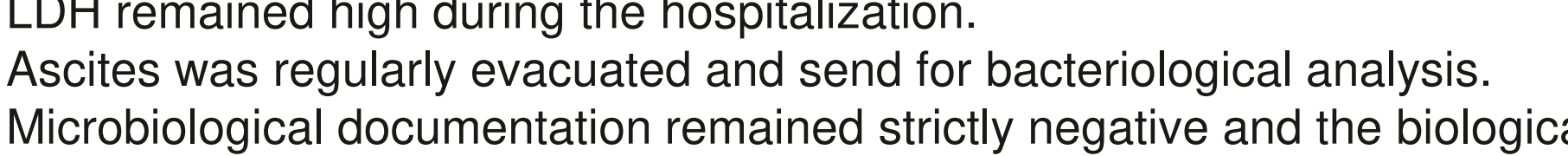

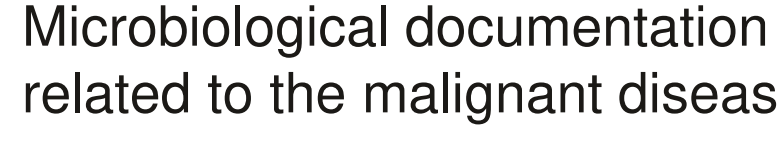

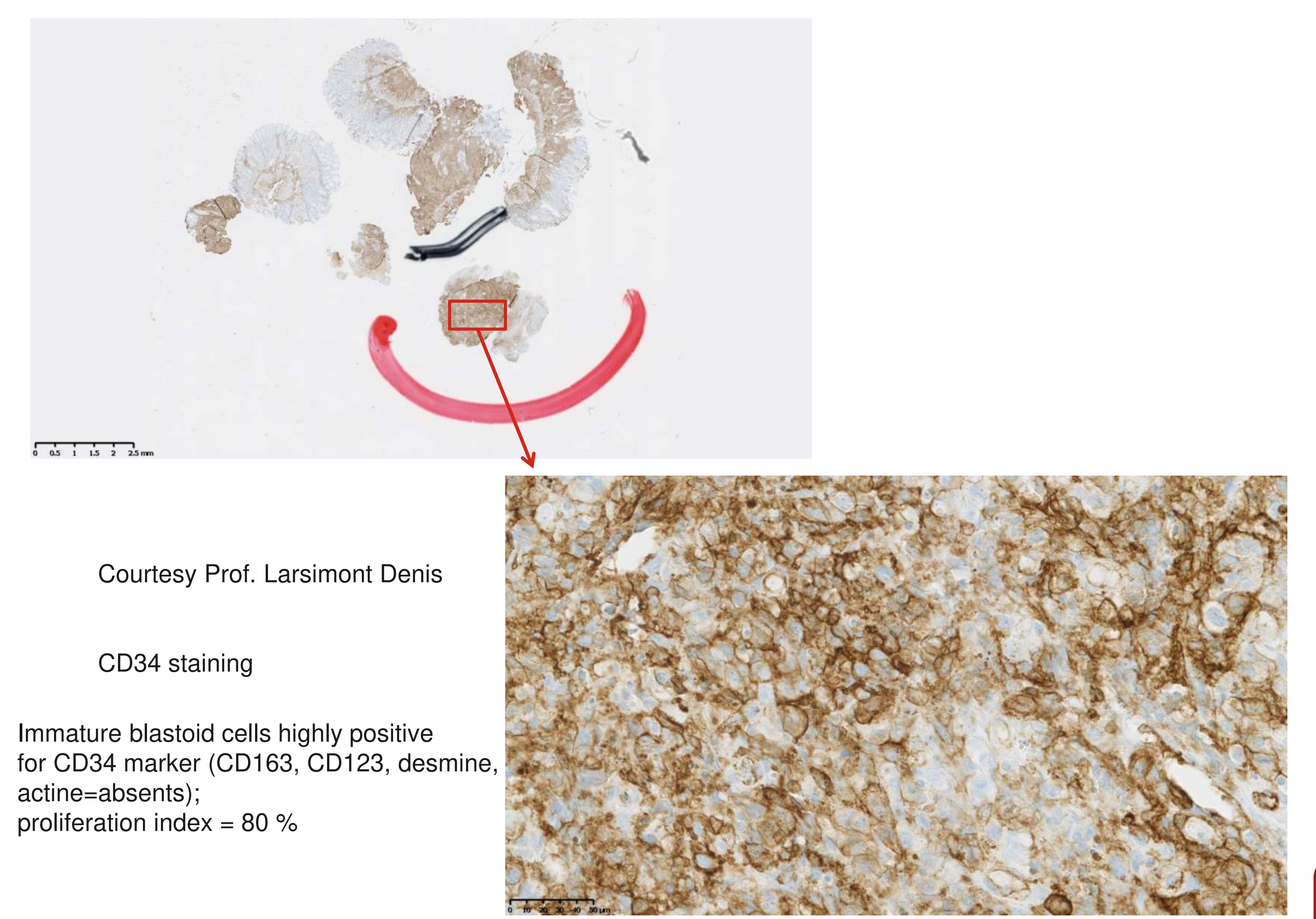

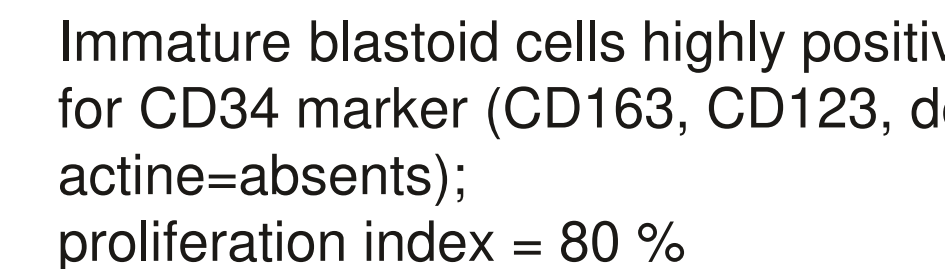

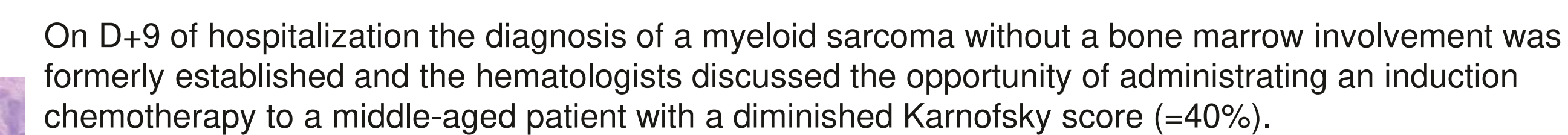

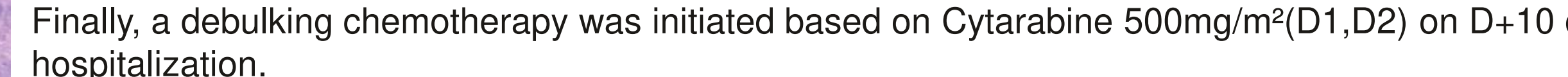

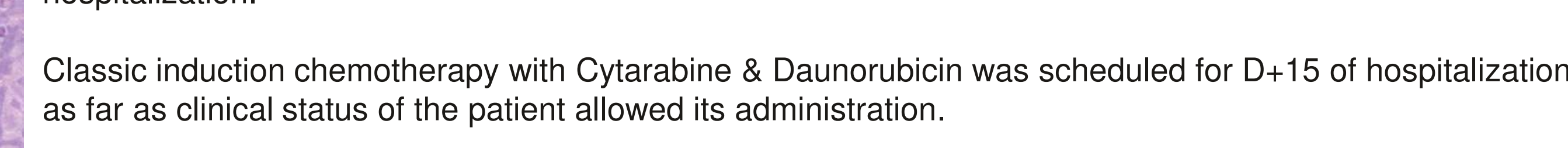

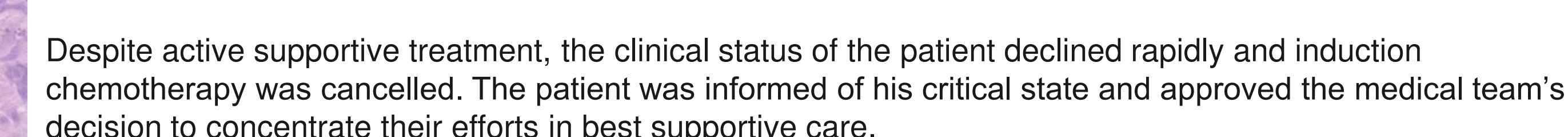

The patien b became comatasse and bibogical paraneters w wosenend.
Discussion

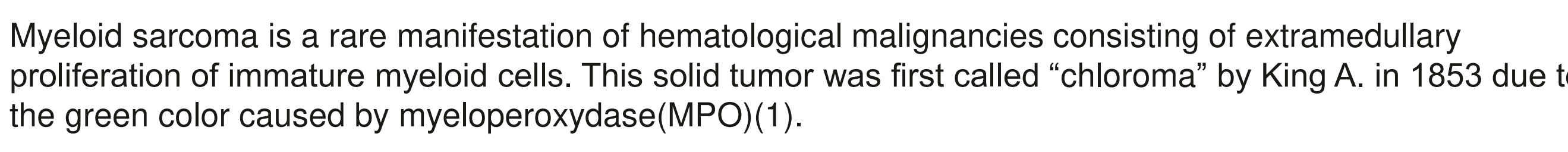

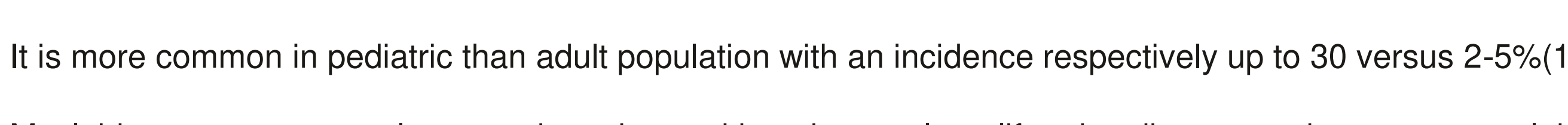

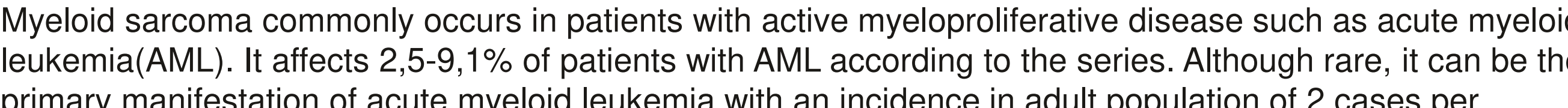

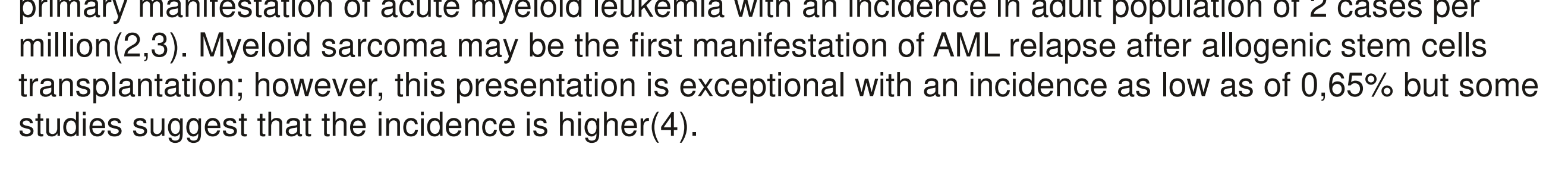

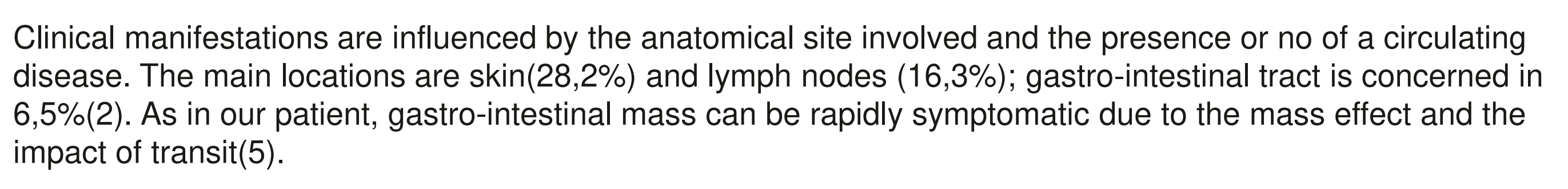

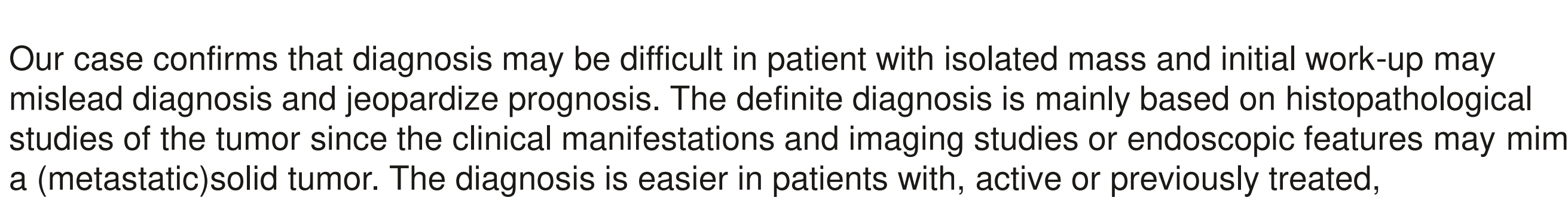

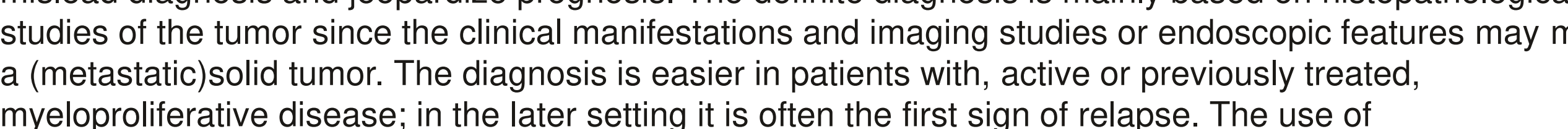

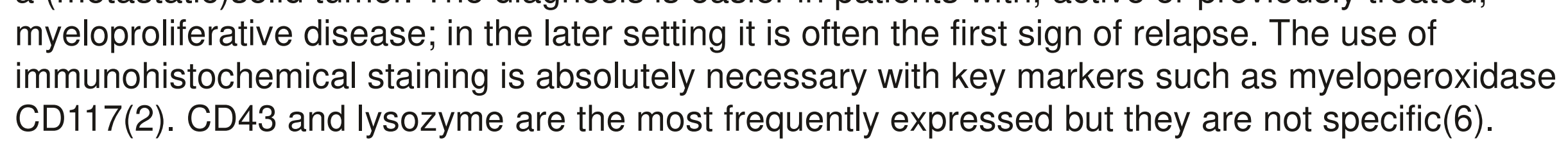

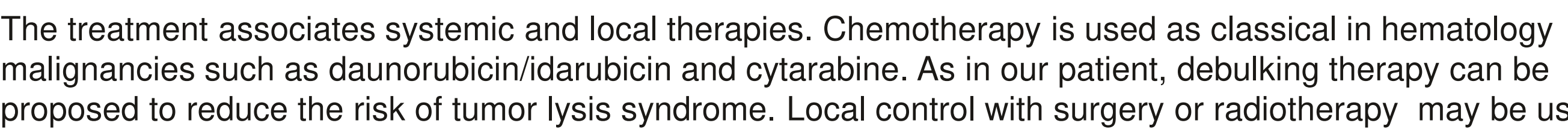

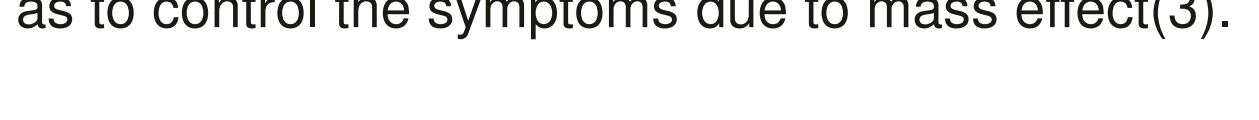

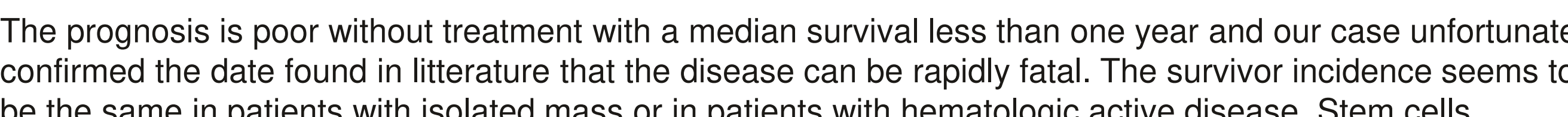

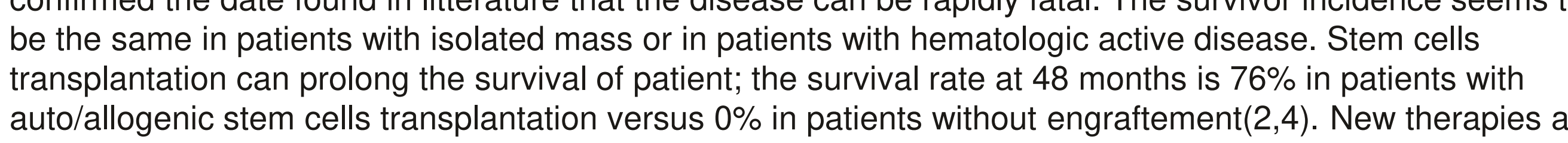

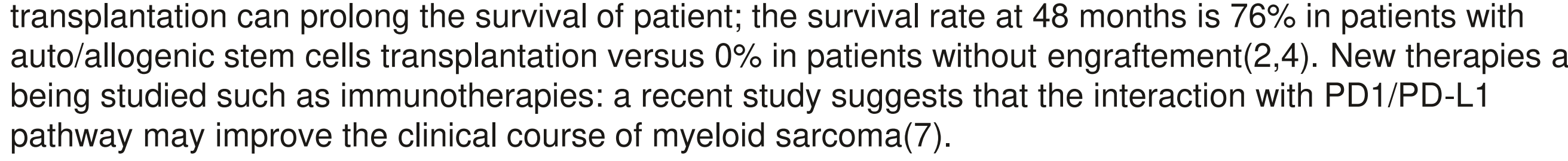

\section{References}

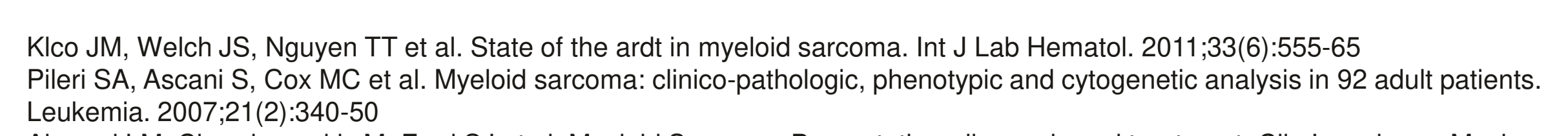

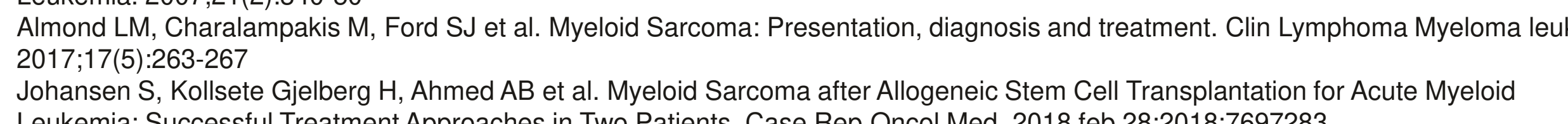

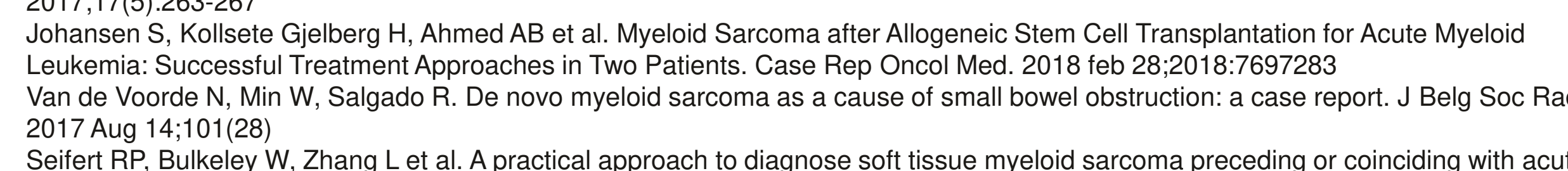

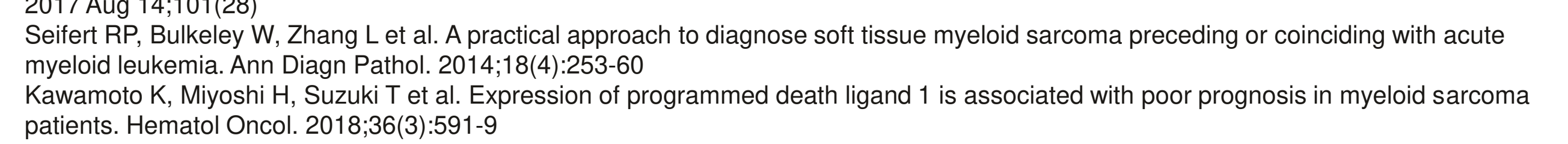

